\title{
Hey Doctor! Did You Wash Your Smartphone?
}

\author{
Craig S. Brown, MD, Ben E. Biesterveld, MD, and Seth A. Waits, MD
}

Department of Surgery, University of Michigan, 1500 E Medical Center Dr., Ann Arbor, MI, USA.

J Gen Intern Med 35(7):2193-4

DOI: $10.1007 / \mathrm{s} 11606-020-05847-6$

(c) Society of General Internal Medicine 2020

$\mathrm{S}$ martphones are indispensable tools of modern healthcare. In times of normalcy or crisis, smartphones greatly extend the capacity of medical providers - allowing us to simultaneously check labs, review relevant literature, track wound progress, and facilitate instantaneous communication with our care teams and patients. But they travel with us everywhere - in our pocket and lab coat, to the restroom and to patient rooms. Not surprisingly, nearly $100 \%$ of healthcare provider mobile phones show growth of bacterial pathogens [1]. Phones swabbed from intensive care settings have shown high rates of multidrug-resistant bacteria such as Pseudomonas aeruginosa, Acinetobacter, Staphylococcus aureus, and vancomycin-resistant Enterococcus [2]. Highly pathogenic viral isolates of norovirus, rotavirus, and respiratory syncytial virus are also known to reside on our smartphones. COVID-19 is likely the same, with emerging evidence suggesting that isolates are viable on inanimate surfaces for up to $72 \mathrm{~h}$ [3].

At a time of crisis, everyday practices which reduce the risk of healthcare-associated infection attract a large and vocal audience. From social media to morning television, lessons on how to properly wash our hands are dusted off and told as new - but these lessons are tried and true. "Clean Care is Safer Care" programs have demonstrated significant reductions in healthcare-associated infections and have been endorsed by the Centers for Disease Control and World Health Organization. But hands are not our only source for healthcareassociated infection. Inanimate objects, such as stethoscopes, have long been recognized as important vectors for bacterial and viral transmission. While definitively linking contaminated devices to hospital-acquired infections has proved to be difficult, stethoscopes have been shown to harbor pathogenic bacteria and these bacteria have been shown capable of transmission to provider hands and back to patient's skin [4]. Healthcare workers have been shown to rarely clean their stethoscopes between patients, even though cleaning significantly decreases the bacterial load $[5,6]$.

Received March 23, 2020

Revised March 23, 2020

Accepted April 7, 2020

Published online April 20, 2020
Local quarantines and shelter in place orders due to the COVID-19 pandemic are necessitating the rapid adoption of new telehealth techniques. New policy efforts to waive Medicare restrictions on telehealth will pave the way for providers to accelerate adoption of e-visits and other technology-related healthcare interventions, thus creating ever more contact with our smartphones and tablets. Additionally, as a means to spread knowledge, many providers are turning to social media (e.g., Twitter) as a means to share experiences, spread knowledge, and live the experience within a supporting community. These "on the fly" communications often take place at the point of patient care, offering a point of exposure for these connected devices.

Thankfully, mobile technology is nearly universally easy to clean. Large technology companies such as Apple ${ }^{\circledR}$ have updated guidelines on smartphone cleaning, suggesting that smartphone cleaning can be as simple as application of $70 \%$ isopropyl alcohol or disinfecting wipe [7]. These are easy interventions and have been shown to reduce viral and bacterial loads by $>99 \%$. The average American touches their phone 47 times per day; this simple intervention can help to keep those touches clean.

A new microbial threat to our patients will always be on the horizon. By asking our medical and surgical teams to clean their smartphones daily and keep them away from patient care areas when possible, we hope to decrease pathogenic exposure. Look at the bright side-keeping the smartphone in our pocket may even help us to pay better attention to the people who matter the most, our patients.

Corresponding Author: Craig S. Brown, MD; Department of Surgery, University of Michigan, 1500 E Medical Center Dr., Ann Arbor, MI 48109, USA (e-mail: brcraig@med.umich.edu).

\section{Compliance with Ethical Standards:}

Conflict of Interest: The authors declare that they do not have a conflict of interest.

\section{REFERENCES}

1. Simmonds R, Lee D, Hayhurst E. Mobile phones as fomites for potential pathogens in hospitals: microbiome analysis reveals hidden contaminants. J Hosp Infect 2019; published online Oct 1. DOI:https://doi.org/10.1016/ j.jhin.2019.09.010.

2. Loyola S, Gutierrez L, Avendaño E, Severino N, Tamariz J. Multidrugresistant bacteria isolated from cell phones in five intensive care units: exploratory dispersion analysis. Germs 2018; 8: 85-91. 
3. van Doremalen N, Bushmaker T, Morris DH, et al. Aerosol and surface stability of SARS-CoV-2 as compared with SARS-CoV-1. $N$ Engl $J$ Med 2020: NEJMc2004973.

4. Bernard L, Kereveur A, Durand D, et al. Bacterial contamination of hospital physicians' stethoscopes. Infect Control Hosp Epidemiol 1999; 20: 626-8.

5. O'Flaherty N, Fenelon L. The stethoscope and healthcare-associated infection: a snake in the grass or innocent bystander? J Hosp Infect 2015; 91: 1-7.

6. Parmar RC, Valvi CC, Sira P, Kamat JR. A prospective, randomised, double-blind study of comparative efficacy of immediate versus daily cleaning of stethoscope using 66\% ethyl alcohol. Indian J Med Sci 2004; 58: $423-30$.

7. How to clean your Apple products - Apple Support. https://support.apple. com/en-us/HT204172 (accessed March 17, 2020).

Publisher's Note: Springer Nature remains neutral with regard to jurisdictional claims in published maps and institutional affiliations. 